\title{
New Modeling of Switching Devices Considering Power Loss in Electromagnetic Transients Program Simulation
}

\author{
Seung-Tak Kim*, Jung-Wook Park* and Seung-Mook Baek ${ }^{\dagger}$
}

\begin{abstract}
This paper presents the modeling of insulated-gate bipolar transistor (IGBT) in electromagnetic transients program (EMTP) simulation for the reliable calculation of switching and conduction losses. The conventional approach considering the physical property of switching devices requires many attribute parameters and large computation efforts. In contrast, the proposed method uses the curve fitting and interpolation techniques based on typical switching waveforms and a userdefined component with variable resistances to capture the dynamic characteristics of IGBTs. Therefore, the simulation time can be efficiently reduced without losing the accuracy while avoiding the extremely small time step, which is required in simulation by the conventional method. The EMTP based simulation includes turn-on and turn-off transients of IGBT, saturation state, forward voltage of free-wheeling diode, and reverse recovery characteristics, etc. The effectiveness of proposed modeling for the EMTP simulation is verified by the comparison with experimental results obtained from practical implementation in hardware.
\end{abstract}

Keywords: Conduction loss, Curve fitting, Electromagnetic transients program simulation, Insulated-gate bipolar transistor, Interpolation, Modeling, Switching loss

\section{Introduction}

The insulated-gate bipolar transistor (IGBT) is being widely used in many power-electronics based applications such as the pulse-width-modulation (PWM) converters and inverters. Its conduction and switching losses are the main cause of power dissipations in device. Therefore, their exact calculation in simulation is strongly required for the effective design of power electronic circuits and the protection of IGBTs before the actual devices are made in practice. In particular, the accurate prediction of switching losses is extremely important in designing the thermal management system $[1,2]$. This is because the temperature of components will be increased by switching losses if the system is designed with high switching frequency to improve its performance.

The most electromagnetic transients programs (EMTPs) can provide the modeling for many power electronic devices in simulation as the form of on-off switches with two-state resistors. This simple representation is sufficiently accurate to simulate electrical behaviors of system. However, in terms of switching loss, the more accurate estimation method is highly required to predict the maximum junction temperatures and overall power converter efficiencies correctly [3]. To achieve this goal, the approaches using the complete model of switching

$\dagger$ Corresponding Author: Divison of Electrical, Electronic, and Control Engineering, Kongju National University, Cheonan, Korea. (smbaek@kongju.ac.kr)

* School of Electrical and Electronic Engineering, Yonsei University, Korea. (\{miso2me,jungpark\}@yonsei.ac.kr)

Received: November 4, 2015; Accepted: February 10, 2016 device can be applied. Several detailed models [4-18] including the parasitic capacitances and inductances have been already proposed with a fully analytical treatment or sufficient experimental tests. Unfortunately, these models require the intensive computational efforts. Moreover, the information obtained from practical tests under some specific conditions is not always available in most cases. In other words, because each simulation provides the valid results only for the corresponding case, neither a general conclusion nor a clear physical insight into switching process is easily obtained with these models.

Meanwhile, the other approaches have been proposed by calculating the power loss as the product of current and voltage waveforms. In [9] , the type of hysteresis switching is studied considering its switching pattern in a power converter, which affects the power loss. The ideal sinusoidal collector and load currents are used in [10] and [11]. The significant signal conditioning method to estimate losses under aperiodic switching is shown in [12]. The relationships between switching energy and collector current are also considered in [13]. In particular, the more detailed information in switching characteristics is required in [1]. These simulation approaches require many attribute parameters to estimate the switching loss. Moreover, the drop in overall efficiency of system due to the conduction and switching losses is not directly reflected in each simulation time step. Therefore, for the proper modeling compatible with EMTP simulation, the power loss by switching must be efficiently calculated while providing both accuracy and fast simulation time. In addition, the generality of model must be guaranteed without regard to 
the used switching pattern and frequency, and even applied control methods.

This paper proposes the new modeling of IGBT in EMTP simulation for the effective power loss calculation while overcoming the limitations of conventional methods. Firstly, the curve fitting and interpolation techniques for estimation are applied based on the information of performance curves in datasheet. Then, the user-defined component with variable resistances is developed to capture the dynamic characteristics of IGBTs. Furthermore, the proposed modeling enables to calculate the overall efficiency of system correctly in every simulation time step by observing the associated waveforms with the appropriate time interval. This results in reducing the simulation time when compared to the relatively smaller time step used in conventional methods.

The proposed modeling is implemented by using the power system computer aided design/electromagnetic transients including DC (PSCAD/EMTDC ${ }^{\circledR}$ ) software, which is the one of widely used EMTP programs. Then, its effectiveness in simulation is verified by comparing the experimental results obtained from practical system in hardware, which is the photovoltaic (PV) grid-connected power conditioning system (PCS) of $3 \mathrm{~kW}$.

\section{Proposed Modeling of Switching Devices for EMTP Simulation}

The accurate modeling of switch devices such as IGBT and diode is described in this section with the consideration of their conduction and switching losses. As an example of its application, the total loss of semiconductors in PM75CLA120, which is the commercial intelligent power module (IPM) used in a three-phase inverter of $75 \mathrm{~A}$ and $1200 \mathrm{~V}$, is calculated. This IPM includes a protection circuit for short-circuit current, overheating, and lowvoltage. Also, it has six IGBTs and six freewheeling diodes. The more detailed information is given in its datasheet [14]. Nevertheless, it is insufficient to estimate its power loss exactly.

As mentioned previously, the proposed modeling method uses the numerical values obtained by the polynomial curve fitting with respect to performance curves in the datasheet of PM75CLA120. Then, it is ready to fully capture the internal characteristics of IGBTs and diodes.

\subsection{Structure of proposed modeling}

In general, the switching devices such as thyristor, diode, IGBT, and breaker, etc., used in the EMTP are modeled with two-state resistors, which change their state from onresistance to off-resistance, or vice versa. On the other hand, its accuracy in a switching event depends on the time step in the EMTP simulation. In this case, the interpolation

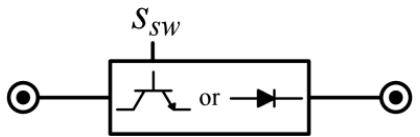

(a)

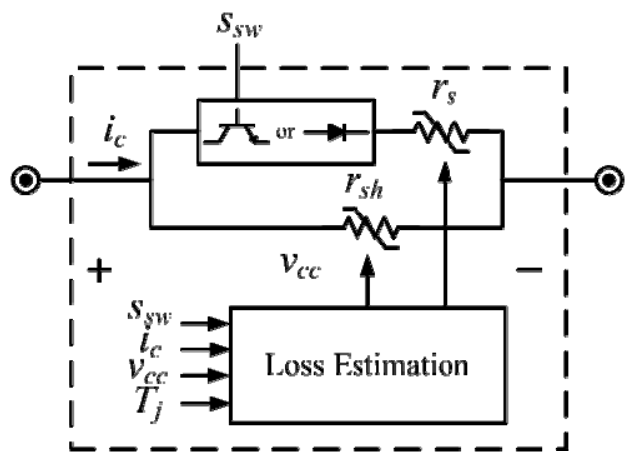

(b)

Fig. 1. The structure of proposed modeling for a switching device to apply the interpolation technique: (a) conventional model; (b) proposed model.

technique can solve the inaccurate modeling problem, which might be caused by the fixed time step. This is because it allows the solution to go back to any instant in time required to model the switching behavior. For example, a diode would cause the solution to back in time when its current was exactly zero before it switches, whereas the fixed time step would switch the diode state in the next time step after the zero crossing [15-16]. The structure of proposed modeling to apply the interpolation technique is shown in Fig. 1.

Likewise the conventional model, the proposed model still uses the original switching on and off signals of controller, as shown in Fig. 1. Note that the power loss is related with the voltage drop across switching device and the magnitude of current flowing through that element. Therefore, to take into account this, the proposed model considers the power consumed in circuit by current and voltage. In other words, it uses two variable resistors, rs and rsh in Fig. 1(b), to model the above power consumption. The series-connected resistor, $r_{s}$ accounts for the power consumed by the conduction and turn-on switching losses. Also, the parallel-connected resistor, $r_{s h}$ is used to model the turn-off switching loss and the reverse recovery loss only if the device is the type of diode.

\subsection{Switching loss estimation of IGBT}

Typical switching waveforms of IGBT are shown in Fig. 2 [17]. One is the current, $i_{c}$ flowing through the switch, and the other is the voltage across switch, $v_{c c}$. When the signal of switch operation, $s_{s w}$ in Fig. 1(b) is applied, the turn-on and turn-off switching losses occur at the corresponding switching times, $t_{\text {on }}$ and $t_{\text {off }}$, respectively. For their calculation, the turn-on voltage, $v_{c c_{-} \text {on }}$, the turn-on 
Table 1. Information for input and output of each function used to obtain the measurements

\begin{tabular}{c|c|c|c|c}
\hline $\begin{array}{c}\text { Input of } \\
\mathrm{S} / \mathrm{H}\end{array}$ & $\begin{array}{c}\text { Edge } \\
\text { Detector A }\end{array}$ & $\begin{array}{c}\text { Time of } \\
\text { Mono-stable }\end{array}$ & $\begin{array}{c}\text { Edge } \\
\text { Detector B }\end{array}$ & Output \\
\hline$v_{c c}$ & positive & $t_{o n}$ & positive & $v_{c c \text { on }}$ \\
\hline$v_{c c}$ & negative & $\begin{array}{c}t_{\text {off }} \text { (IGBT) } \\
t_{r r} \text { (Diode) }\end{array}$ & negative & $\begin{array}{c}v_{c c_{\text {off }}} \text { (IGBT) } \\
-v_{c c \text { off }} \text { (Diode) }\end{array}$ \\
\hline$i_{c}$ & positive & $t_{o n}$ & negative & $i_{c \_o n}$ \\
\hline$i_{c}$ & negative & $\begin{array}{c}t_{\text {off }} \text { (IGBT) } \\
t_{r r} \text { (Diode) }\end{array}$ & positive & $i_{c_{-} \text {off }}$ \\
\hline
\end{tabular}

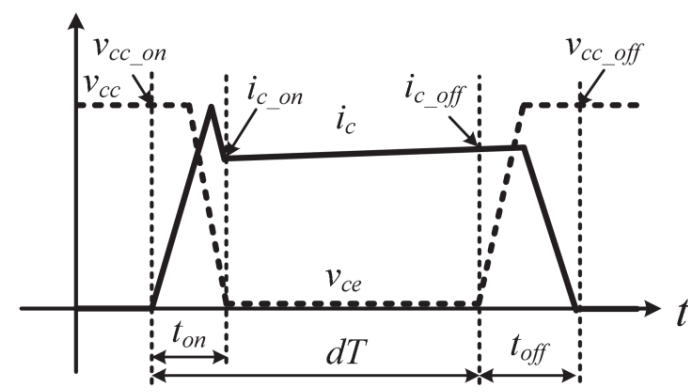

Fig. 2. Typical switching waveforms of IGBT.

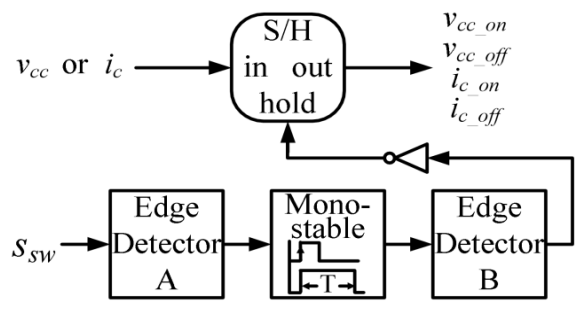

Fig. 3. The process in EMTP to obtain the measurements.

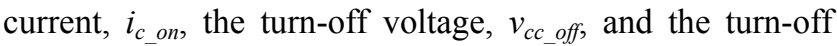
current, $i_{c_{-} \text {off }}$ are measured. These measurements vary depending on the operation of switch and the status of circuit.

The process in EMTP to obtain the measurements, $v_{c c_{-} \text {on }}$, $i_{c \text { on }}, v_{c c \text { off }}$, and $i_{c \text { off }}$ from $v_{c c}$ and $i_{c}$ measured inside the model is shown in Fig. 3. After the operation of switch is changed, there is the delay for turn-on and turn-off switching times, or for reverse recovery time, $t_{r r}$ of diode. Then, the measurements are properly obtained by using the sample and hold $(\mathrm{S} / \mathrm{H})$, the mono-stable function, and two edge detectors. Table I gives the information for input and output of each function in Fig. 3.

As shown in Fig. 4(a), the turn-on switching loss is easily obtained from the datasheet at $v_{c c}$ rated of $600 \mathrm{~V}$. Also, the collector current shows the sudden change when it is about $40 \mathrm{~A}$. Note that the PV PCS of $3 \mathrm{~kW}$ used in experimental test operates with its rated current of $13.6 \mathrm{~A}$. Therefore, this abrupt change does not cause any problems to verify the performance of proposed modeling. If the current is over than $40 \mathrm{~A}$, the higher order polynomial might be required to estimate this sudden change. In this paper, the fourth-order polynomial is used for the appropriate accuracy.

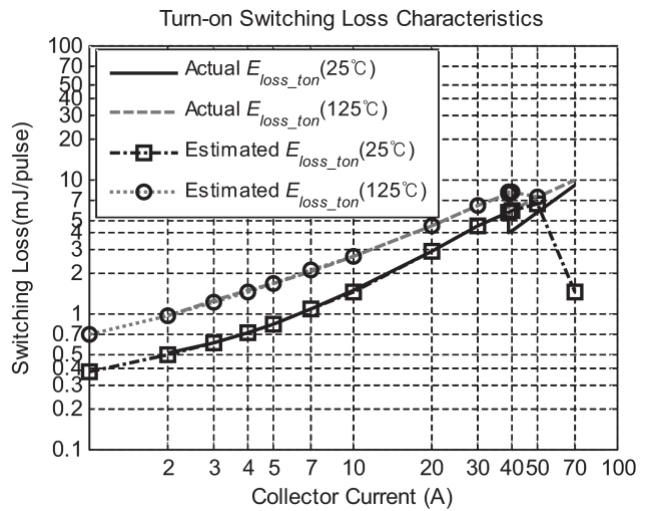

(a)

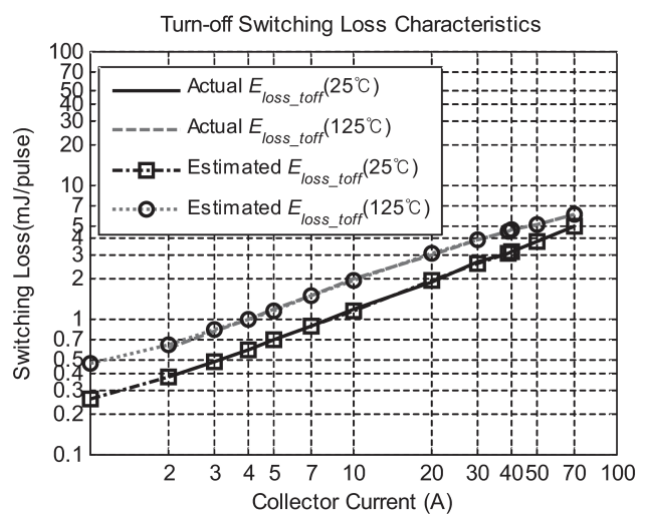

(b)

Fig. 4. Estimation results of turn-on and turn-off switching losses: (a) turn-on; (b) turn-off.

When the junction temperature, $T_{j}$ is $25^{\circ} \mathrm{C}$ and $125^{\circ} \mathrm{C}$, the fourth-order polynomials to approximate the turn-on switching loss, $E_{\text {loss_ton }}\left({ }^{\circ} \mathrm{C}\right)$, are represented as (1) and (2), respectively.

$$
\begin{aligned}
& E_{\text {loss_ton }}\left(25^{\circ} \mathrm{C}\right)=\sum_{k=0}^{4} c_{\text {ton_k } k}\left(25^{\circ} \mathrm{C}\right) \cdot i_{c_{-} \text {on }}^{k} \\
& E_{\text {loss_ton }}\left(125^{\circ} \mathrm{C}\right)=\sum_{k=0}^{4} c_{\text {ton_k } k}\left(125^{\circ} \mathrm{C}\right) \cdot i_{c_{-} \text {on }}^{k}
\end{aligned}
$$

where the coefficients, $c_{\text {ton } k}$, vary depending on the junction temperature to reflect its characteristics. And, it is assumed that the switching losses have the approximately linear relationship with junction temperature [18]. Therefore, they can be expressed with the linear form as (3),

$$
c_{\text {ton_k }}=d_{11_{-} \text {ton_k }} \cdot T_{j}+d_{2_{-} \text {ton_k }}
$$

where the $T_{j}$ is $25{ }^{\circ} \mathrm{C}$ or $125{ }^{\circ} \mathrm{C}$. Also, the coefficients, $d_{1_{-} \text {ton } \_k}$ and $d_{2_{-} \text {ton } k}$ are calculated as,

$$
d_{1_{-} \text {ton } \_}=\frac{c_{\text {ton_k }}\left(125^{\circ} \mathrm{C}\right)-c_{\text {ton_k }}\left(25^{\circ} \mathrm{C}\right)}{125-25}
$$




$$
\begin{aligned}
& d_{2 \_t o n_{-} k}=c_{\text {ton_ } k}\left(25^{\circ} \mathrm{C}\right)-25 \cdot d_{1 \_t o n_{-} k} \\
& \text { or } c_{\text {ton } n_{-} k}\left(125^{\circ} \mathrm{C}\right)-125 \cdot d_{1_{-} \text {ton }_{-} k}
\end{aligned}
$$

Because the power is proportional to the square of voltage, the eqns. (1) and (2) must be modified by considering the $v_{\text {c__on }}$. Then, the estimated $E_{\text {loss_ton }}$ is represented as

$$
E_{\text {loss_ton }}=\frac{v_{c c_{-} \text {on }}^{2}}{v_{c c_{-} \text {rated }}^{2}} \sum_{k=0}^{4}\left(d_{1_{-} \text {ton_k }} \cdot T_{j}+d_{2_{-} \text {ton_ } k}\right) \cdot i_{c_{-} \text {on }}^{k}
$$

Moreover, the resistance must be also considered for the estimation of $E_{\text {loss ton }}$. Because the time step, $\Delta t$ is fixed in the EMTP simulation, the switching losses are consumed in several time steps during the turn-on and turn-off times. In addition, they might be calculated incorrectly due to the instantaneous voltage across switch. Therefore, the proposed modeling uses the fixed resistance for only single switching event.

Thereafter, the value of variable series-connected resistor, $r_{s}$ is computed by the estimated $E_{\text {loss_ton }}$ with the maximum and minimum values of resistor connected in parallel, $r_{s h}$ and internal on-state resistor of switch, respectively. If $v_{c c_{-} \text {on }}$ is increased, $E_{\text {loss_ton }}$ is also increased by (6). That is, when the switch is turned on, the value of $r_{s}$ in the proposed modeling is determined as

$$
r_{s}=\frac{v_{c c_{-} o n}^{2}}{E_{\text {loss_ton }}}\left\lceil\frac{t_{\text {on }}}{\Delta t}\right\rceil \cdot \Delta t, \quad r_{s h}=r_{\max }
$$

where the value of $r_{\max }$ must be sufficiently large to make the branch with $r_{s h}$ open. Therefore, the $r_{\max }$ of $1 \mathrm{M} \Omega$ is used in this study.

In the similar manner, when the switch is turned off, the estimated $E_{\text {loss toff }}$ and the value of variable resistor connected in parallel, $r_{s h}$ are computed by (8) and (9), respectively. Note that the maximum value of $r_{s}$ is applied in this case. Finally, the good estimation results are shown in Fig. 4(b).

$$
\begin{gathered}
E_{\text {loss_toff }}=\frac{v_{c c_{-} \text {off }}^{2}}{v_{c c_{-} \text {rated }}^{2}} \sum_{k=0}^{4}\left(d_{1_{-} \text {toff } \_k} \cdot T_{j}+d_{2_{-} \text {toff } \_k}\right) \cdot i_{c_{-} \text {off }}^{k} \\
r_{s}=r_{\max }, \quad r_{s h}=\frac{v_{c c_{-} \text {off }}^{2}}{E_{\text {loss_toff }}}\left[\frac{t_{\text {off }}}{\Delta t}\right] \cdot \Delta t
\end{gathered}
$$

\subsection{Switching loss estimation of diode}

Differently from the IGBT, the switching state of diode is determined depending on the direction of current. Based on the interpolation technique described in sub-section II- $A$, its current can become zero without regard to the simulation time step. Therefore, the operating state of diode can be accurately reflected in the proposed modeling.

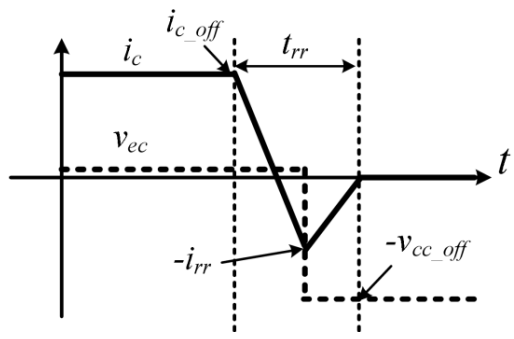

Fig. 5. Typical switching waveforms of diode.

For the modern fast-recovery diode used with IGBTs, its turn-on loss is negligible because it is very small (less than $1 \%$ ) when compared to its turn-off loss [19]. However, the reverse recovery behavior during the turn-off time causes the considerable loss. Also, it affects the turn-on loss of IGBT. In general, the turn-off loss data of diode is not given in the datasheet. Therefore, the characteristics of its reverse recovery switching loss are investigated and then estimated.

The typical switching waveforms of diode are shown in Fig. 5. With the information of reverse recovery current $\left(i_{r r}\right)$ and reverse recovery time $\left(t_{r r}\right)$ from the datasheet as shown in Fig. 6, its switching loss is estimated. Similarly to the previous estimation method for the IGBT, the characteristic curves of diode are approximated by (10) and (11) with the fourth-order polynomial in the ranges, where the value of correct recovery current is less than $40 \mathrm{~A}$. This is because the sudden change of temperature occurs at that point as the (turn-on) case of IGBT.

$$
\begin{aligned}
& i_{r r}=\sum_{k=0}^{4}\left(d_{1_{-} i r r_{-} k} \cdot T_{j}+d_{2_{-} i r r_{-} k}\right) \cdot i_{c_{-} \text {off }}^{k} \\
& t_{r r}=\sum_{k=0}^{4}\left(d_{1_{-} t r r_{-} k} \cdot T_{j}+d_{2_{-} t r r_{-} k}\right) \cdot i_{c_{-} \text {off }}^{k}
\end{aligned}
$$

where the $T_{j}$ is still $25^{\circ} \mathrm{C}$ or $125^{\circ} \mathrm{C}$.

Then, the estimated $E_{\text {loss_drr }}$ [20] and the value of associated resistor, $r_{s h}$ are represented as

$$
\begin{gathered}
E_{\text {loss_drr }}=0.25 \cdot t_{r r} \cdot i_{r r} \cdot v_{c c_{-} o f f} \frac{v_{c c_{-} o f f}^{2}}{v_{c c_{-} r a t e d}^{2}} \\
r_{s}=r_{\text {max }}, \quad r_{s h}=\frac{v_{c c_{-} \text {off }}^{2}}{E_{\text {loss_drr }}}\left[\frac{t_{r r}}{\Delta t}\right] \cdot \Delta t
\end{gathered}
$$

Note that the maximum value of $r_{s}$ is still applied in this case. It is known form the results in Fig. 6 that the proposed method still provides the good estimation performance for $i_{r r}$ and $t_{r r}$ of diode. As the result, the proposed modeling for its reverse recovery switching loss is acceptable.

\subsection{Conduction loss estimation of IGBT and diode}

The nonlinear characteristics of conduction loss of IGBT 


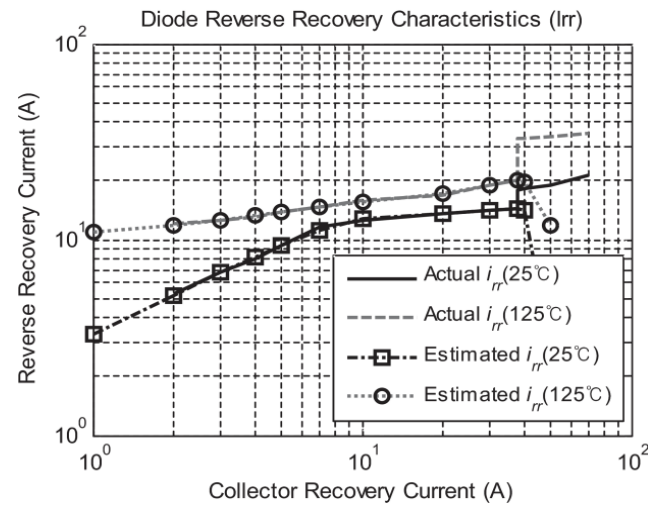

(a)

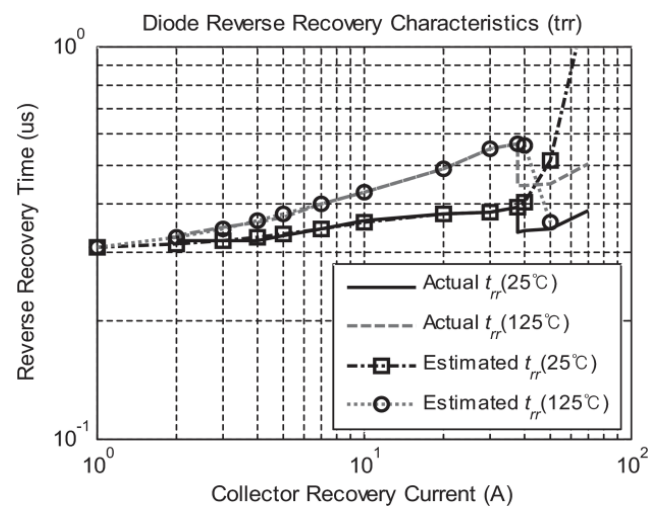

(b)

Fig. 6. Estimation results of reverse recovery switching loss of diode: (a) reverse recovery current; (b) reverse recovery time.

and diode cannot be fully captured by the conventional modeling with the only fixed internal on-state resistor. To overcome this limitation, the proposed modeling estimates the nonlinear relationships between voltage drop across the switch and current flowing through that device. These relationships are shown in Fig. 7.

One is the corrector-emitter saturation voltage characteristics to the collector current of IGBT. The other is the collector recovery current characteristics to the corrector- emitter voltage of diode.

Then, the collector-emitter voltage, $v_{c e}$ is approximated by the same fourth-order polynomial as the previous cases. In other words, the $v_{c e}$ is estimated by (14), and the value of associated resistor, $r_{s}$ is calculated by (15).

$$
\begin{gathered}
v_{c e}=\sum_{k=0}^{4}\left(d_{1_{-} v c e+k} \cdot T_{j}+d_{2_{-} v c e_{-} k}\right) \cdot i_{c}^{k}, \\
E_{\text {loss_cond }}=v_{c e} \cdot i_{c} \\
r_{s}=\frac{v_{c e}}{i_{c}}, \quad r_{s h}=r_{\max }
\end{gathered}
$$

The results in Fig. 7 show the good estimation performance for conduction loss, $E_{\text {loss_cond }}$ by the proposed modeling.

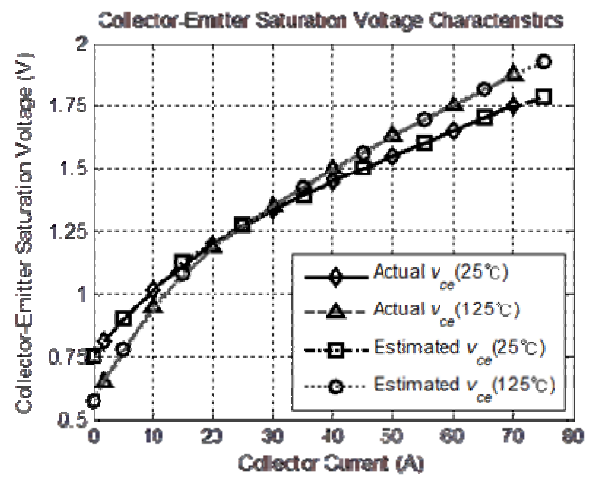

(a)

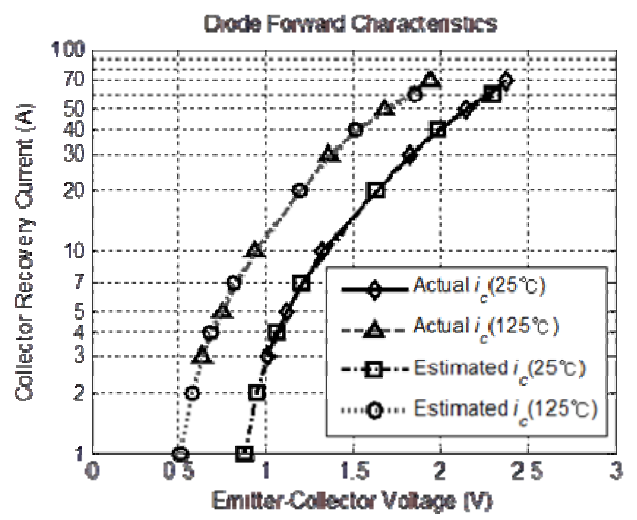

(b)

Fig. 7. Estimation results of conduction loss: (a) characteristics of IGBT; (b) characteristics of diode.

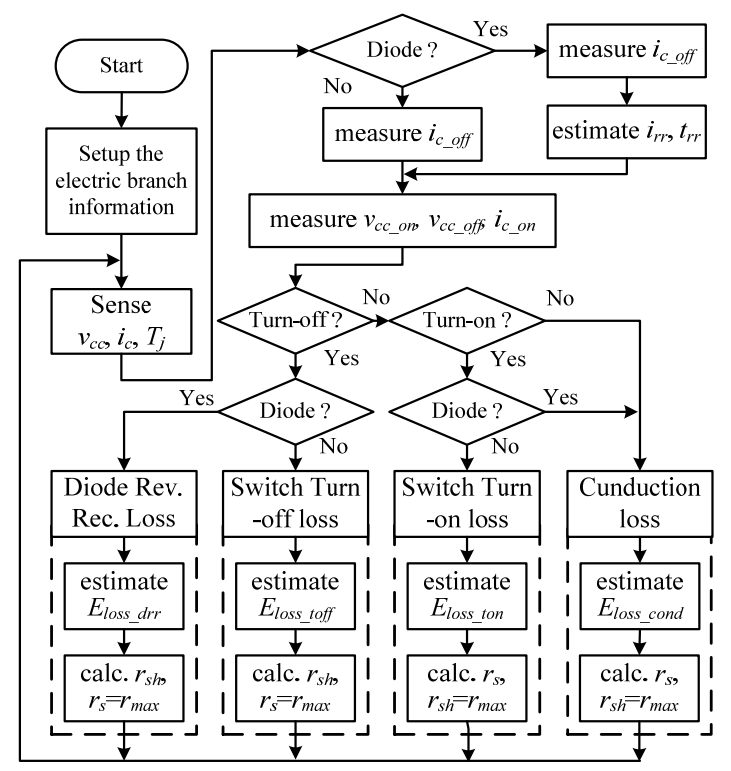

Fig. 8. The overall procedure to implement the proposed modeling in EMTP simulation.

\subsection{Implementation of proposed modeling in EMTP}

For the most cases that require several switching devices in a power converter, the proposed modeling is implemented 
in the EMTP simulation by the procedure as shown in Fig. 8.

Firstly, it starts by setting up the electric branch structure as shown in Fig. 1(b) with the series and parallel resistors. Then, it measures the current, voltage, and junction temperature of switching device. For the diode, it estimates the $i_{r r}$ and $t_{r r}$ by (10) and (11), respectively, after obtaining the $i_{c \text { off }}$. Thereafter, it also measures $v_{c c \text { on }}, v_{c c \text { off }}$, and $i_{c \text { on }}$. It decides whether it operates in turn-on or turn-off time.

For the diode in turn-off time, its reverse recovery switching loss, $E_{\text {loss_drr }}$ is estimated by (12). For the case of turn-on time, it calculates the conduction loss, $E_{\text {loss_cond }}$ by estimating the collector-emitter voltage, $v_{c e}$ by (14). On the other hand, for the case of IGBT, its turn-on switching loss, $E_{\text {loss_ton }}$ and turn-off loss, $E_{\text {loss_toff }}$ are estimated by (6) and (8), respectively. Also, the values of associated resistors, $r_{s h}$ and $r_{s}$, are calculated correspondingly to their suitable cases.

\section{Simulation Results}

The performances of proposed modeling are evaluated by time-domain simulation based on the PSCAD/EMTDC ${ }^{\circledR}$ software. The PV PCS of $3 \mathrm{~kW}$ is tested with a fullydetailed topology model with proposed switching device modeling method, which consists of a DC/DC boost converter and a full-bridge PWM inverter with the switching frequency of $20 \mathrm{kHz}$. It is shown in Fig. 9.

When the junction temperature is $60^{\circ} \mathrm{C}$, the simulation results of IGBT in the lower side and diode in the upper side of the DC/DC boost converter are shown in Figs. 10 and 11, respectively. The switch signal has the duty ratio of 0.275 , and the turn-on signal of IGBT is applied at $t=10$ $\mu \mathrm{s}$.

In Fig. 10(a), the voltage of $v_{c c}$ drops after the delay of $1.2 \mu \mathrm{s}$ from $t=10 \mu \mathrm{s}$ when the simulation time-step is 0.3 $\mu$ s. In contrast, it shows the delay of $2 \mu$ s when the simulation time-step is $2 \mu \mathrm{s}$. The circuit simulation including the voltage of $v_{c c}$ drop is carried out in accordance with the time step. This means that the turn-on switching time mainly depends on the simulation time-step. Also, the current of IGBT and power loss (sum of conduction and

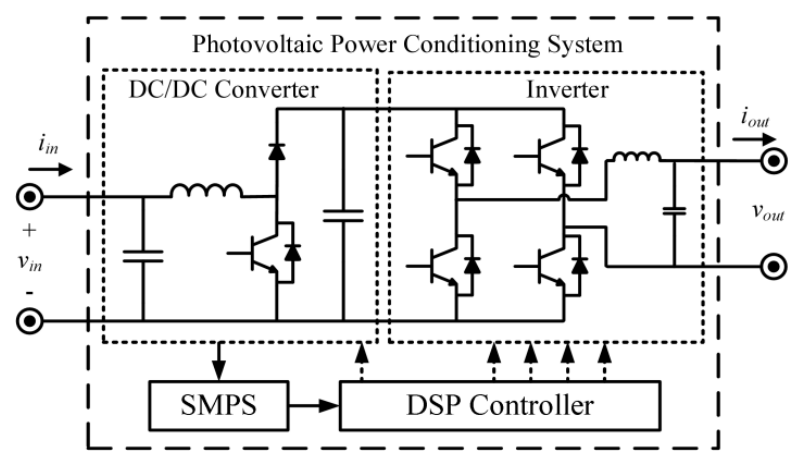

Fig. 9. The configuration of PV PCS of $3 \mathrm{~kW}$. switching losses) are shown in Figs. 10(b) and 10(c), respectively. In Fig. 10(c), the energy of power loss for 0.3 $\mu \mathrm{s}$ and $2 \mu \mathrm{s}$ time-steps are $1.52 \mathrm{~mJ}$ and $1.59 \mathrm{~mJ}$ per switching period, respectively. Note that they are very close. On the contrary, the peak values of current and power loss (particularly for the turn-on switching loss) are

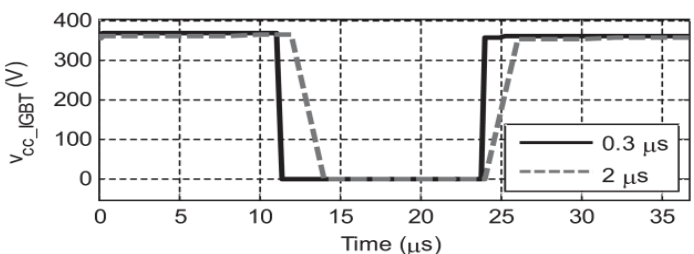

(a)

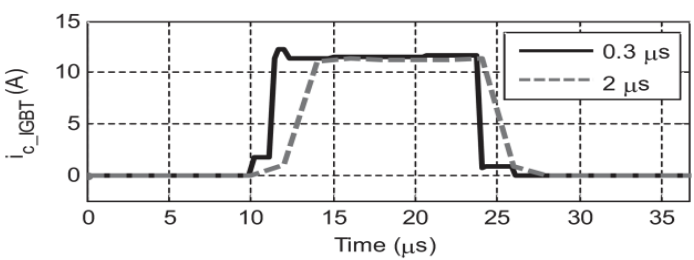

(b)

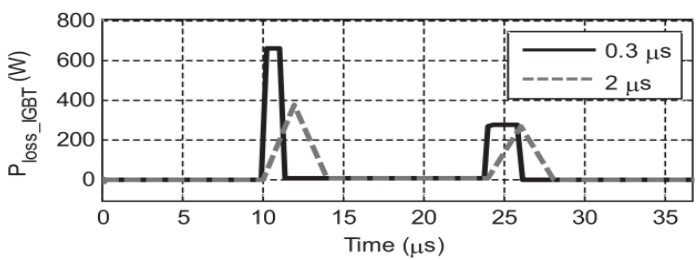

(c)

Fig. 10. Results for the IGBT: (a) voltage, (b) current, (c) power loss.

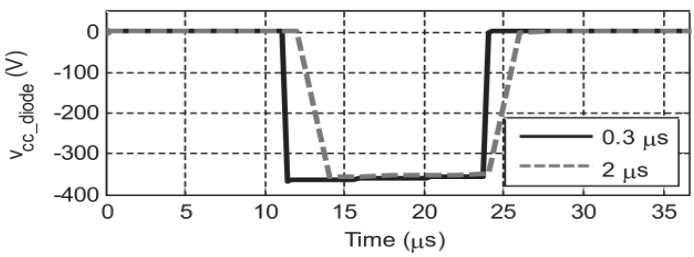

(a)

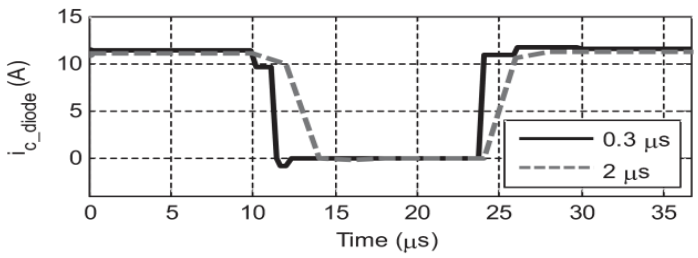

(b)

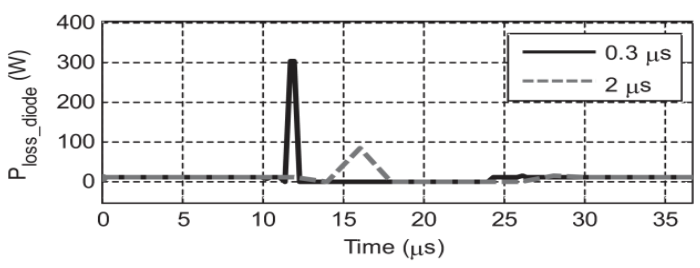

(c)

Fig. 11. Results for the diode: (a) voltage, (b) current, (c) power loss. 
different depending on the simulation time-step.

When the IGBT is off, the voltage across diode becomes zero. If the IGBT turns on after the delay depending on simulation time-step, the state of diode is changed from closed to open, as shown in Fig. 11(a). It is known from the result of Fig. 11(b) that its current is exactly zero by the interpolation technique when the diode is completely turned off. Also, the result of Fig. 11(c) show that the proposed modeling generates the similar energies of reverse recovery switching loss, which are $0.71 \mathrm{~mJ}$ and $0.66 \mathrm{~mJ}$ for the cases of time-steps of $0.3 \mu \mathrm{s}$ and $2 \mu \mathrm{s}$,

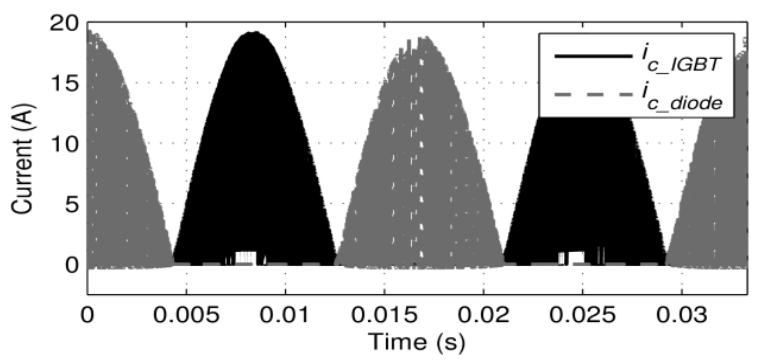

(a)

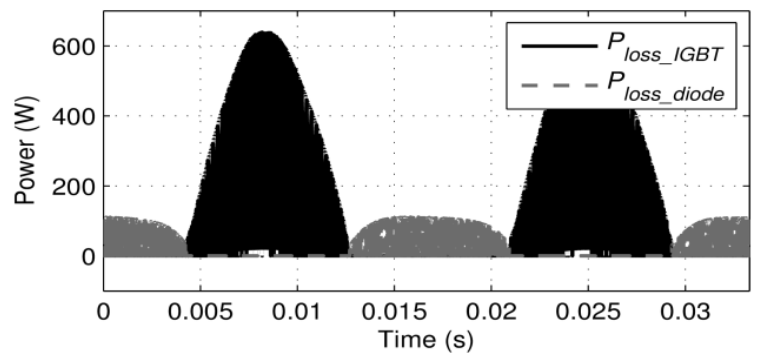

(b)

Fig. 12. Simulation results of upper left IGBT and diode in PWM inverter: (a) current, (b) power loss.

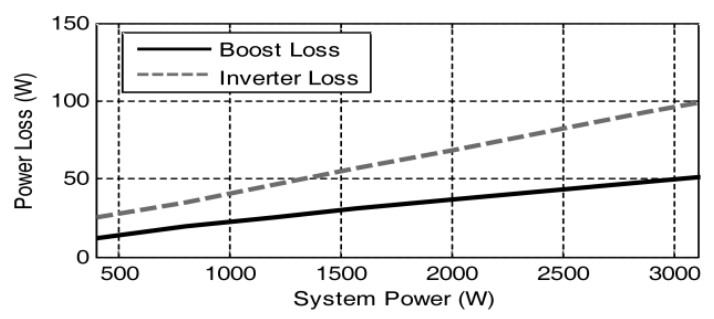

(a)

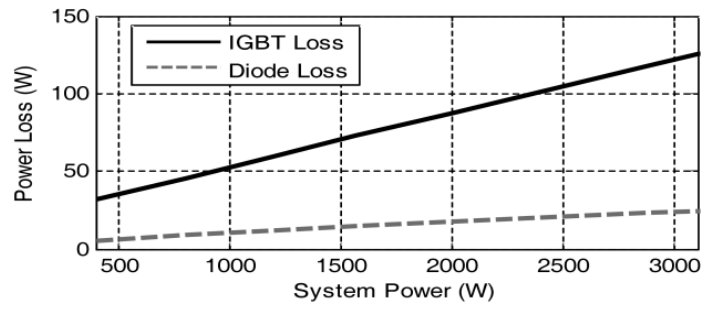

(b)

Fig. 13. Power loss analysis of proposed modeling: (a) converter type; (b) switch type. respectively. Note that these values are close even though their peak values are very different.

For the PWM inverter in Fig. 9, the current and power loss responses of upper left IGBT and diode are shown in Fig. 12. The peak value of current flowing the IGBT is the same as that of half waveform of current flowing to grid side, which is the output of PV PCS. Also, it is observed that the power loss of IGBT depends on the magnitude of current. The similar results are applied to the diode except that the current flowing the diode is phase-shifted by 180 , and the power loss consumed in diode is less than that of IGBT.

The more detailed power loss analysis of PV PCS is shown in Fig. 13. It is observed that the relationship between power loss and output power of system is linear without regard to the type of converter and switch. Also, the power loss of inverter is about two times that of boost converter. This is because two switching devices in inverter operate in one turn-on and turn-off switching action. Similarly to the result in Fig. 12(b), the result of Fig. 13(b) show that the power loss of IGBT is much greater than that of diode.

\section{Experimental Results}

\subsection{Hardware implementation}

The effectiveness of proposed modeling for the EMTP simulation is verified by the experimental test implemented in hardware as shown in Fig. 14(a). The photograph of real PV PCS of $3 \mathrm{~kW}$ is shown in Fig. 14(b).

The DC/DC boost converter and DC/AC inverter are controlled independently with the switching frequency of $20 \mathrm{kHz}$. In particular, their PWM controllers are implemented by the digital signal processor (DSP) of TMS320F2812. The boost converter is operated with the maximum-power-point-tracking (MPPT) algorithm based on the perturbation and observation (P\&O) method [21]. The inverter is connected to a commercial electrical outlet of $220 \mathrm{~V}$. Also, it controls the DC capacitor voltage in realtime. To operate the DSP, control circuit, switching devices, and sensors, the switching mode power supply (SMPS) is applied to adjust their suitable voltages and to supply the power. The specifications of PV PCS are given in Table 2.

As shown in Fig. 14(c), the voltage and current outputs are measured by using the digital phosphor Tektronix oscilloscope of the DPO4054. Also, its output power is measured from the power analysis application module of DPO4PWR, which is attached to the oscilloscope of DPO4054.

\subsection{Experimental results}

The experimental results of system efficiency under various operating conditions are shown in Fig. 15. The 


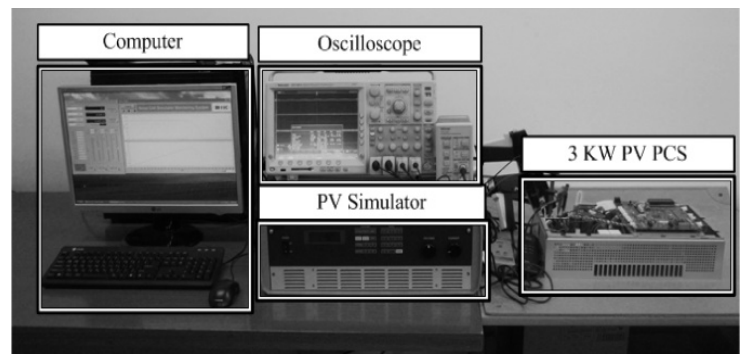

(a)

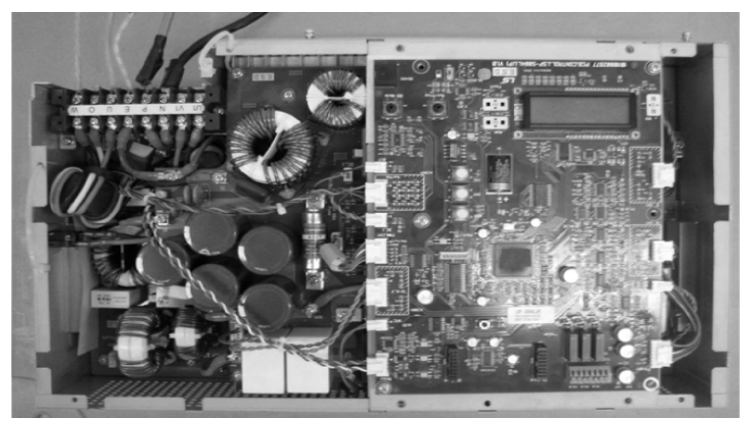

(b)

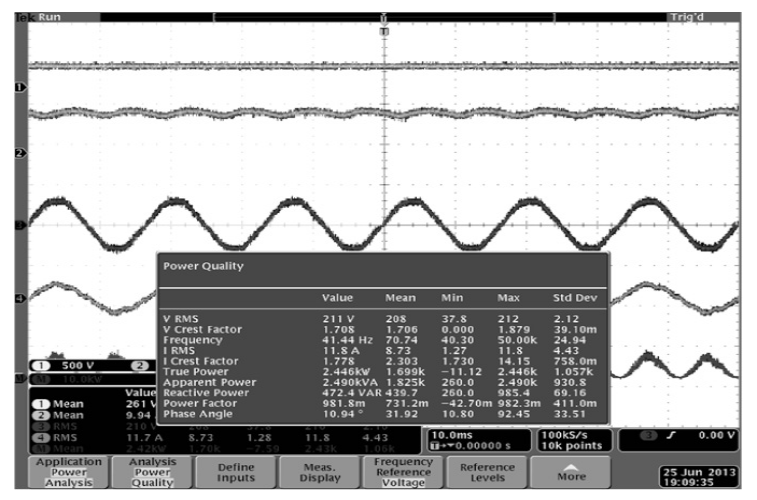

(c)

Fig. 14. Hardware implementation: (a) hardware set-up for experimental test, (b) PV PCS of $3 \mathrm{~kW}$, (c) experimental results: voltage and current outputs.

Table 2. Specifications of PV PCS

\begin{tabular}{c|c|c}
\hline System & Parameters & Values \\
\hline \multirow{2}{*}{ PV simulator } & Output current range & $0-20 \mathrm{~A}$ \\
\cline { 2 - 3 } & Output voltage range & $10-500 \mathrm{~V}$ \\
\hline DC/DC boost & Rated power & $3 \mathrm{~kW}$ \\
\hline converter & MPPT algorithm & P\&O \\
\hline \multirow{3}{*}{$\begin{array}{c}\text { DC/AC } \\
\text { inverter }\end{array}$} & Rated power & $3 \mathrm{~kW}$ \\
\cline { 2 - 3 } & Rated DC voltage & $375 \mathrm{~V}$ \\
\cline { 2 - 3 } & Switch frequency & $20 \mathrm{kHz}$ \\
\cline { 2 - 3 } & Type & Single-phase full-bridge \\
\hline SMPS & Rated power & $25 \mathrm{~W}$ \\
\hline
\end{tabular}

total 160 measurements are taken and indicated by "o" in Fig. 15. The results show that the efficiencies are in the ranges from $79 \%$ at $325 \mathrm{~W}$ to $95 \%$ at $3.2 \mathrm{~kW}$. The simulation result by the conventional modeling shows

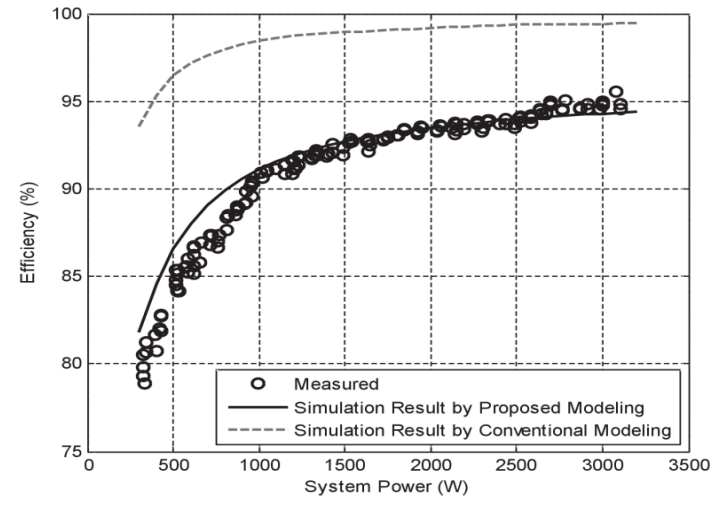

Fig. 15. The comparison of experimental and simulation results for system efficiencies.

Table 3. Comparison Results of RMSE and Error in European efficiency

\begin{tabular}{c|c|c}
\hline Simulation method & RMSE BY (16) & Absolute error in $\eta_{\text {euro }}$ \\
\hline Conventional modeling & 7.726 & 7.723 \\
\hline Proposed modeling & 1.162 & 0.656 \\
\hline
\end{tabular}

the large difference from the measurements. In contrast, the system efficiency is calculated accurately with the simulation by proposed modeling. This verifies that the proposed method estimates the power loss correctly.

For the numerical comparison, the root-mean-square error (RMSE) and the European efficiency, which is the weighted conversion efficiency and used for the particular application such as this PV PCS, are considered. Firstly, the RMSE is computed as

$$
R M S E=\sqrt{\frac{\sum_{i=1}^{n}\left(\eta_{\text {measured }, i}-\eta_{\text {model }, i}\right)^{2}}{n}}
$$

where $n$ is the number of samples, $\eta_{\text {measured }, i}$ is the efficiency measured in experimental test, and $\eta_{\text {model, } i}$ is the efficiency obtained in simulation test. Then, it is calculated in the range from $300 \mathrm{~W}$ to $3.2 \mathrm{~kW}$ with the increase of $100 \mathrm{~W}$.

On the other hand, the European efficiency is the useful comparative tool in this study because the output of PV PCS can be affected by the external condition such as weather. It aims to approximate the integral of conversion efficiency versus time over the entire day. The European efficiency, $\eta_{\text {euro }}$ is defined as follows [22], [23]:

$$
\begin{aligned}
\eta_{\text {euro }}=0.03 \eta_{5 \%}+0.06 \eta_{10 \%}+0.13 \eta_{20 \%} \\
+0.10 \eta_{30 \%}+0.48 \eta_{50 \%}+0.20 \eta_{100 \%}
\end{aligned}
$$

where $\eta_{i} \%$ is the conversion efficiency at $i \%$ of the rated power output.

The comparison results for the RMSE in (16) and absolute error in $\eta_{\text {euro }}$ are given in Table III. It is clearly observed that the proposed modeling outperforms the conventional one (which is carried out by the built-in 
function of PSCAD/EMTDC ${ }^{\circledR}$ software with the only twostate resistors) significantly for the computation of efficiency. In particular, for the $\eta_{\text {euro }}$, the proposed modeling provides the very accurate performance with the error of $0.656 \%$, which is less than $1 \%$.

\section{Conclusions}

This paper proposed the new modeling of insulated-gate bipolar transistor (IGBT) and diode to estimate their switching and conduction losses by using the interpolation and curve fitting techniques. The proposed modeling was implemented for the effective use in the electromagnetic transients program (EMTP) simulation while avoiding the extremely small time step required to capture the full characteristics of switching devices.

Both simulation and experimental tests were carried out to verify the usefulness of proposed modeling. In particular, the photovoltaic $(\mathrm{PV})$ grid-connected power conditioning system (PCS) of $3 \mathrm{~kW}$ was implemented in hardware for experimental test. The given results verified that the proposed method estimates the power loss of switching devices very accurately, and therefore it can be preferably used to calculate the system efficiency in the EMTP simulation.

\section{Acknowledgement}

This work was supported in part by the National Research Foundation of Korea (NRF) grant funded by the Korea government (MEST) (No. 2011-0028065) and in part by the Power Generation \& Electricity Delivery Core Technology Program of the Korea Institute of Energy Technology Evaluation and Planning (KETEP) granted financial resource from the Ministry of Trade, Industry \& Energy, Republic of Korea (No. 20141020402340).

\section{References}

[1] A. D. Rajapakse A. M. Gole, and P. L.Wilson, "Electromagnetic transient simulation models for accurate representation of switching losses and thermal performance in power electronic systems," IEEE Trans. Power Del., vol. 20, no. 1, pp. 319-327, Jan. 2005.

[2] Z. Xu, M. Li, F. Wang, Z. Liang, "Investigation of Si IGBT operation at 200 C for traction applications," IEEE Trans. Power Electron., vol. 28, no. 5, pp. 2604-2615, May 2013.

[3] Y. L. Xiong, S. Sun, H. W. Jia, P. Shea, and Z. J. Shen, "New physical insights on power MOSFET switching losses," IEEE Trans. Power Electron., vol. 24, no. 2, pp. 525-531, Feb. 2009.
[4] Y. Ren, M. Xu, J. Zhou, and F. C. Lee, "Analytical loss model of power MOSFET," IEEE Trans. Power Electron., vol. 21, no. 2, pp. 310-319, Mar. 2004.

[5] W. Eberle, Z. Zhang, Y. F. Liu, and P. C. Sen, "A practical switching loss model for buck voltage regulators," IEEE Trans. Power Electron., vol. 24, no. 3, pp. 700-713, Mar. 2009.

[6] Y. Wu, M. A. Shafi, A. M. Knight, and R. A. McMahon, "Comparison of the effects of continuous and discontinuous PWM schemes on power losses of voltage-sourced inverters for induction motor drives," IEEE Trans. Power Electron., vol. 26, no. 1, pp. 182-191, Jan. 2011.

[7] S. Ji, Z. Zhao, T. Lu, L. Yuan, and H. Yu, "HVIGBT physical model analysis during transient," IEEE Trans. Power Electron., vol. 28, no. 5, pp. 2616-2624, May 2013.

[8] M. Rodriguez, A. Rodriguez, P. F. Miaja, D. G. Lamar, and J. S. Zuniga, "An insight into the switching process of power MOSFETs: An improved analytical losses model," IEEE Trans. Power Electron., vol. 25, no. 6, pp. 1626-1640, Jun. 2010.

[9] A. M. Bazzi, P. T. Krein, J. W. Kimball, and K. Kepley, "IGBT and diode loss estimation under hysteresis switching," IEEE Trans. Power Electron., vol. 27, no. 3, pp. 1044-1048, Mar. 2012.

[10] C. Edrington, O. Vodyakho, M. Steurer, S. Azongha, F. Fleming, and M. Krishnamurthy, "Power semiconductor loss evaluation in voltage source IGBT converters for three-phase induction motor drives," in Proc. Vehicle Power and Propulsion Conf., 2009. VPPC '09. IEEE, Dearborn, MI, Sep. 2009, pp. 1434-1439.

[11] G. J. Su and P. Ning, "Loss modeling and comparison of VSI and RB-IGBT based CSI in traction drive applications," in Proc. Transportation Electrification Conf. and Expo (ITEC), 2013 IEEE, Detroit, MI, Jun. 2013, pp. 1-7.

[12] B. T. Cassimere, S. D. Sudhoff, B. N. Cassimere, D. C. Aliprantis, and M.D. Swinney, "IGBT and PN junction diode lossmodeling for system simulations," in Proc. IEEE Int. Elec. Mach. Drives Conf. (IEMDC), San Antonio, TX, May 2005, pp. 941-949.

[13] C. N. Ho, H. Breuninger, S. Pettersson, G. Escobar, L. A. Serpa and A. Coccia, "Practical design and implementation procedure of an interleaved boost converter using $\mathrm{SiC}$ diodes for PV applications," IEEE Trans. Power Electron., vol. 27, no. 6, pp. 2835-2845, Jun. 2012.

[14] Mitsubishi Electric Corp. (2005, May.). PM75CLA120 Datasheet [Online]. Available: $\mathrm{http}: / /$ www.mitsubishielectric.com/semiconductors/ datasheet/

[15] G. D. Irwin, D. A. Woodford, and A. Gole, "Precision simulation of PWM controller," in Proc. Int. Conf. Power System Transients, Rio de Janeiro, Brazil, Jun. 
2001, pp. 301-306.

[16] B. DeKelper, L. Dessaint, K. Al-Haddad, and H. Nakra, "A comprehensive approach to fixed-step simulation of switched circuits," IEEE Trans. Power Electron., vol. 17, no. 2, pp. 216-224, Mar. 2002.

[17] J. W. Kimball, "Modeling controlled switches and diodes for electro-thermal simulation," in Proc. IEEE Power Electron. Specialists Conf., June 2005, pp. 2175-2179.

[18] P. R. Palmer, E. Santi, J. L. Hudgins, X. Kang, J. C. Joyce, and P. Y. Eng, "Circuit simulator models for the diode and IGBT with full temperature dependent features," IEEE Trans. Power Electron., vol. 18, no. 5, pp. 1220-1229, Sep. 2003.

[19] A. D. Rajapakse, A.M. Gole and P. L. Wilson, "Approximate loss formula for estimation of IGBT switching losses through EMTP-type simulations," presented at the 6th Int. Conf. of Power Systems Transients, Montreal, QC, Canada, Jun. 2005.

[20] Mitsubishi Electric Corp. (2012, Dec.). IPM L-series application note. [Online]. Available:

http://www.mitsubishielectric.com/semiconductors/ products/powermod/note/

[21] E. Roman, R. Alonso, P. Ibanez, S. Elorduizapatarietxe and D. Goitia, "Intelligent PV module for grid-connected PV systems," IEEE Trans. Ind. Electron., vol. 53, no. 4, pp. 1066-1073, Jun. 2006.

[22] G.-S. Seo. K.-C. Lee and B.-H. Cho, "A New DC Anti-Islanding Technique of Electrolytic CapacitorLess Photovoltaic Interface in DC Distribution Systems," IEEE Trans. Power Electron., vol. 28, no. 4, pp. 1632-1641, Apr. 2013.

[23] C. Rodriguez and G. A. J. Amaratunga, "Longlifetime power inverter for photovoltaic AC modules," IEEE Trans. Ind. Electron., vol. 55, no. 7, pp. 2593-2601, Jul. 2008.

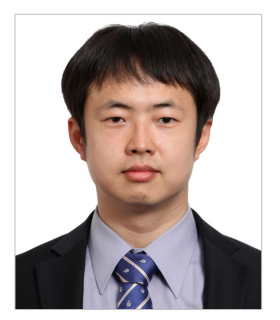

Seung-Tak Kim was born in Ulsan, Korea. He received the B.S. and Ph.D. degrees from the School of Electrical and Electronic Engineering, Yonsei University, Seoul, Korea, in 2009 and 2014, respectively. He is currently a Principal Research Engineer in the Hyundai Mobis Co. Ltd., Yongin-si, Gyeonggi-do, Korea. He was a Lead Researcher in the Hyundai Heavy Industries Co. Ltd., during 2014-2015. His research interests are in control of renewable energies based systems, hardware implementation of grid-connected inverter with photovoltaic and energy storage devices, energy management system for stabilization of distributed generation systems, and control of a bidirectional on board charger for Plug-in Hybrid Electric Vehicle (PHEV).

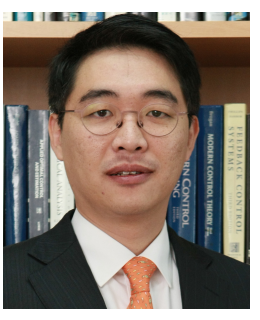

Jung-Wook Park was born in Seoul, Korea. He received the B.S. degree (summa cum laude) from the Department of Electrical Engineering, Yonsei University, Seoul, Korea, in 1999, and the M.S.E.C.E. and Ph.D. degrees from the School of Electrical and Computer Engineering, Georgia Institute of Technology, Atlanta, USA in 2000 and 2003, respectively. He was a Post-doctoral Research Associate in the Department of Electrical and Computer Engineering, University of Wisconsin, Madison, USA during 2003-2004, and a Senior Research Engineer with LG Electronics Inc., Korea during 2004-2005. He is currently an Associate Professor in the School of Electrical and Electronic Engineering, Yonsei University, Seoul, Korea. He is now leading the National Leading Research Laboratory (NLRL) designated by Korea government to the subject of integrated optimal operation for smart grid. His current research interests are in power system dynamics, renewable energies based distributed generations, power control of electric vehicle, and optimization control algorithms. Prof. Park was the recipient of the Young Scientist Presidential Award in 2013 from the Korean Academy of Science and Technology (KAST), Korea.

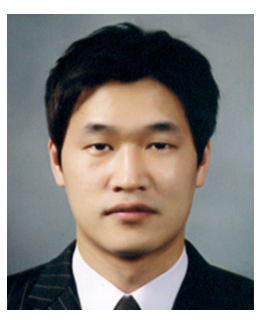

Seung-Mook Baek was born in Seoul, Korea. He received B.S., M.S., and $\mathrm{Ph} . \mathrm{D}$. degrees from the School of Electrical and Electronic Engineering, Yonsei University, Seoul, Korea, in 2006, 2007, and 2010, respectively. $\mathrm{He}$ is currently an Assistant Professor in the Division of Electrical, Electronic and Control Engineering, Kongju National University, Cheonan, Korea. He was a Research Engineer with KEPCO Research Institute, during 2009-2012. His current research interests are in power system dynamics, hybrid systems, optimization control algorithms, real-time simulation, flexible ac transmission system (FACTS) devices, and control of distributed generations 